\title{
Alterações oftálmicas associadas à intoxicação experimental por closantel em caprinos
}

\author{
[Ophthalmic changes associated with the experimental poisoning by closantel in caprine] \\ R. Ecco ${ }^{1}$, C.S.L. Barros $^{2}$, D.L. Graça ${ }^{2}$ \\ ${ }^{1}$ Escola de Veterinária - UFMG \\ Caixa Postal 567 \\ 30123-970 - Belo Horizonte, MG \\ ${ }^{2}$ Departamento de Patologia - UFSM - Santa Maria, RS
}

\begin{abstract}
RESUMO
Alterações oftálmicas foram experimentalmente induzidas em caprinos após superdosagem com o antihelmíntico closantel. Foram usados cinco caprinos com sete a oito meses de idade, produtos do cruzamento da raça Saanen com a Pardo Alpino. Os animais mostraram sinais de intoxicação entre quatro e cinco dias após a administração do closantel. Os sinais clínicos caracterizaram-se principalmente por distúrbios neurológicos centrais e cegueira. Ao exame clínico, observaram-se midríase bilateral, perda do reflexo pupilar à luz e cegueira bilateral. À oftalmoscopia indireta, foram observadas degeneração aguda de retina e papiledema. As alterações crônicas mostravam disco óptico acinzentado, atrofia de vasos e da retina. Nos fundos tapetal e não-tapetal notavam-se áreas de despigmentação e lesões irregulares castanho-amareladas. As alterações histológicas consistiam em perda dos neurônios da camada ganglionar e das células da camada nuclear interna e externa da retina. As alterações agudas no nervo óptico e na substância branca do encéfalo foram de degeneração espongiforme. As alterações crônicas do nervo óptico caracterizavam-se por extensa necrose e infiltração de células Gitter.
\end{abstract}

Palavras-chave: caprino, closantel, alteração oftálmica, retinopatia tóxica, nervo óptico

\begin{abstract}
Ophthalmic alterations were experimentally induced after overdose with the anthelmintic closantel. Five seven to eight- months-old, Saanen x Alpine caprine were used. The animals showed clinical signs of toxicosis four to five days after the administration of closantel. Clinical signs were primarily characterized by central nervous disturbances and blindness. Clinically, bilateral mydriasis, loss of pupillary light reflex, and blindness were observed. At indirect ophthalmoscopic examination, there was acute retinal degeneration and papilledema. Chronic ocular changes consisted of paleness of the optic disc, vascular atrophy, and retinal atrophy. Areas of pigment loss and irregular yellowish-brown foci were present in the tapetal and non-tapetal fundus. Histological alterations consisted of neuronal loss in the ganglion cell layer and depletion of cells in both the outer and inner nuclear layers of the retina. Acute changes of spongy degeneration were noted in the optic nerve and in the cerebral white matter. Chronic lesions in the optic nerve were characterized by extensive necrosis and infiltration by Gitter cells.
\end{abstract}

Keywords: closantel, ophthalmic changes, toxic retinopathy, optic nerve, caprine

\section{INTRODUÇ̃̃O}

O closantel [N-\{5-cloro-4-[(4-clorofenol) cianometil]-2-metilfenol\}-2-hidroxi 3,5-diiodo benzamida) é um anti-helmíntico usado em bovinos e pequenos ruminantes, com eficácia contra Haemonchus contortus, larvas de Oestrus ovis, Fasciola hepatica e outros parasitas hematófagos (Michiels et al., 1987; Hennessy et al., 1993). Pertence à classe dos salicilanilídeos

Recebido em 2 de maio de 2007

Aceito em 19 de dezembro de 2007

E-mail: ecco@vet.ufmg.br 
halogenados e age por via oral e intramuscular (Guerrero, 1984; Michiels et al., 1987). Quando o sangue é sugado pelos parasitas, o fármaco, que se encontra ligado às proteínas plasmáticas, age interferindo na síntese de ATP pela mitocôndria das células do parasita, por meio do desacoplamento da fosforilação oxidativa (Van Den Bossche et al., 1979; Michiels et al., 1987).

A intoxicação por closantel tem sido descrita em caprinos (Button et al., 1987; Obwolo et al., 1989; Ecco et al., 1999), bovinos (Pérez et al., 1988), ovinos (Canavessi, 1998; Borges et al., 1999; Barlow et al., 2002) e cães (McEnttee et al., 1995). A dose tóxica nos casos relatados em caprinos foi de duas a quatro vezes (Barlow et al., 2002), cinco vezes (Gill et al., 1999) e 10 vezes (Obwolo et al., 1989; Button et al., 1987) mais altos que a terapêutica.

Os sinais clínicos descritos são: diarréia verdeescura (Obwolo et al., 1989), distúrbios nervosos como pressão da cabeça contra objetos, torcicolo, andar em círculos, depressão acentuada e fraqueza dos membros, principalmente dos pélvicos (Obwolo et al., 1989; Gill et al., 1999), opistótono, nistagmo, hiperestesia, cegueira com midríase bilateral persistente não responsiva à luz, andar desorientado ou em círculos (Pérez et al., 1988; Obwolo et al., 1989; Gill et al., 1999), além de cólica, gemidos e decúbito lateral (Ecco et al., 1999).

As alterações macroscópicas descritas incluem congestão, edema pulmonar, hidropericárdio (Obwolo et al., 1989), metabolização do tecido adiposo, principalmente pericárdico e perirrenal, áreas amareladas (necrose) no fígado (Ecco et al., 1999), congestão e edema cerebral (Canavessi, 1998) e estreitamento da porção intracanalicular do nervo óptico (Gill et al., 1999).

Os achados histopatológicos revelam necrose de coagulação massiva do fígado, atingindo principalmente o lobo esquerdo (Ecco et al., 1999), e alterações no sistema nervoso central e periférico, os quais consistem principalmente de alterações espongiformes na substância branca do encéfalo (Button et al., 1987; Obwolo et al., 1989; Ecco et al., 1999) e do nervo óptico e quiasma óptico (Button et al., 1987; Ecco et al., 1999; Barlow et al., 2002). Ainda, espongiose nos funículos da medula espinhal cervical
(Borges et al., 1999) e malácia com proliferação de células Gitter no mesencéfalo e no nervo óptico (Ecco et al., 1999; Gill et al., 1999) têm sido observadas em ovinos e caprinos intoxicados por closantel.

As alterações oculares decorrentes da intoxicação por closantel são relatadas em caprinos, ovinos e caninos. $\mathrm{Na}$ oftalmoscopia, as alterações descritas nos casos agudos em caprinos e ovinos foram de papiledema e aumento da refletividade da área tapetal (Borges et al., 1999). Papiledema, focos de hemorragia papilar e hiperrefletividade do fundo tapetal foram as lesões relatadas em um cão intoxicado por closantel (McEnttee et al., 1995). As alterações histológicas descritas no bulbo ocular ocorrem principalmente na retina e são caracterizadas por degeneração e necrose (Pérez et al., 1988; Gill et al., 1999).

Este trabalho teve o objetivo de estudar as alterações clínicas e patológicas no bulbo ocular, no sistema nervoso e no fígado de caprinos intoxicados experimentalmente por closantel.

\section{MATERIAL E MÉTODOS}

Para a investigação dos efeitos tóxicos do closantel, foram utilizados cinco caprinos, Saanen x Pardo Alpino, machos, com cerca de oito meses de idade e 28 a $30 \mathrm{~kg}$ de peso vivo. Foram mantidos em baias de alvenaria, com cama de maravalha e alimentados com feno de alfafa e ração para ovinos à vontade. Três animais receberam via oral dose única $100 \mathrm{mg} / \mathrm{kg}$ de closantel ${ }^{1}$ e um recebeu $50 \mathrm{mg} / \mathrm{kg}$. O caprino número 1 recebeu $30 \mathrm{ml}(3000 \mathrm{mg})$ e os de números 2 e $4,28 \mathrm{ml}(2.800 \mathrm{mg})$, numa dosagem 10 vezes maior que a terapêutica. $\mathrm{O}$ de número 3 recebeu $11,5 \mathrm{ml}(1150 \mathrm{mg})$, cinco vezes mais alta que a dosagem terapêutica, e o animal número 5 foi mantido como controle, recebendo alimentação e água à vontade.

Durante o experimento, todos os animais foram examinados diariamente, sendo avaliados comportamento, postura, apetite, aspecto das fezes e da urina, freqüência cardíaca, respiratória e rumenal, além do exame oftálmico. Diariamente, em cada animal, foi realizado

${ }^{1}$ Diantel. IRFA. Química e Biotecnologia Ltda. - Porto Alegre, Brasil. 
exame clínico oftálmico detalhado por meio da oftalmoscopia direta ${ }^{2}$. A oftalmoscopia indireta ${ }^{3}$ e a videoscopia de fundo de olho foram realizadas em todos os indivíduos: dois meses após a administração do fármaco nos caprinos 1 e 2; um mês após, no de número 3; e quatro dias após, no de número 4.

Para a oftalmoscopia direta, os animais foram mantidos em estação e examinados no fundo da baia onde a incidência de luz era menor. Nos primeiros três dias, quando o animal ainda não estava em midríase, utilizou-se instilação de colírio de atropina ${ }^{4}$ para produzir dilatação pupilar. $\mathrm{Na}$ oftalmoscopia indireta binocular, juntamente com a videoscopia de fundo de olho, os animais receberam relaxante muscular (xilazina) $)^{5}$, na dose de $0,05 \mathrm{mg} / \mathrm{kg}$ via intravenosa. $\mathrm{O}$ caprino controle e o caprino número 4 receberam também instilação de colírio de atropina na pupila. Utilizou-se uma lente convexa de 40 dioptrias para permitir a visão global do fundo do olho.

Os animais foram submetidos à eutanásia, com sobredose de tionembutal ${ }^{6}$ sódico $(20 \mathrm{mg} / \mathrm{kg})$ e cloreto de potássio por via intravenosa, conforme preconizada pelo Conselho Federal de Medicina Veterinária. Os caprinos 1,2 e 3 foram eutanasiados três meses após a intoxicação e o 4 o foi oito dias após receber o fármaco. Durante a necropsia, encéfalo, bulbo ocular, nervo óptico, medula espinhal, nervos isquiático e braquial, fígado, rins, baço, linfonodos, coração, pulmões e músculos esqueléticos foram coletados e fixados em formol neutro a $10 \%$ para microscopia de luz. O bulbo ocular inteiro foi fixado nas primeiras $24 \mathrm{~h}$ em solução de éter, álcool etílico e formol neutro $10 \%$ e, após esse período, mergulhado no formol para posterior processamento. Os tecidos fixados foram embebidos em parafina, seccionados a $5 \mu \mathrm{m}$ e corados com hematoxilina e eosina.

\footnotetext{
${ }^{2}$ Ophthalmoscope Heine K180, Heine Optotecnik Herrsching, Alemanha.

${ }^{3}$ Ophthalmoscope H0110. Carl Zeiss Meditec AG Alemanha.

${ }^{4}$ Atropina $1 \%$ colírio. Alcon Laboratório do Brasil - São Paulo, Brasil.

${ }^{5}$ Rompun. Bayer - São Paulo, Brasil.

${ }^{6}$ Thiopentax -Tiopental sódico. Cristália- Produtos químicos farmacêuticos Ltda. - Itapira, Brasil.
}

\section{RESULTADOS}

Três animais (números 1, 2 e 4) apresentaram cegueira como principal quadro clínico no quinto dia após a dosificação. No caprino de número 3 , não foi observada cegueira e no exame oftálmico constataram-se apenas alterações leves como papiledema, no quarto dia após a administração do closantel. No caprino controle, não foram observadas alterações clínicas, macroscópicas ou histológicas.

O número 1 apresentou diarréia no dia seguinte ao da administração do fármaco e desorientação no quinto dia. Ao se locomover no interior da baia, chocava-se contra obstáculos e guiava-se pelo olfato quando se oferecia alimento. Ao ser exposto à luz, observou-se midríase persistente bilateral completa (Fig.1). Na oftalmoscopia, notou-se amarelamento da parte tapetal da retina (hiperrefletividade), que normalmente é azul clara (Fig. 2), mais pronunciado ao redor dos vasos. No sétimo dia, o amarelamento da retina era difuso, havia hiperreflexia, ingurgitamento dos vasos maiores e papiledema. No $10^{\circ}$ dia, o disco óptico estava hemorrágico, os vasos mais delgados (atrofiados), e o tom azul da retina foi substituído por um tom esverdeado, entremeado por áreas amareladas. A partir do $15^{\circ}$ dia, a papila estava esbranquiçada com contornos irregulares e os vasos bastante escuros e delgados. No $20^{\circ}$ dia, áreas acastanhadas de necrose acentuaram-se ao redor da papila, que se mostrava menor, acinzentada e com contornos irregulares. Essas alterações, nos exames subseqüentes, apenas progrediram, aumentando as áreas de necrose. À oftalmoscopia indireta, realizada dois meses após a intoxicação, observaram-se áreas maiores de lesão, principalmente na parte não-tapetal, onde existiam áreas multifocais irregulares $\mathrm{e}$ deprimidas, com fundo castanho-amarelado. Essas estavam distribuídas em maior quantidade na linha de transição entre a tapetal e a nãotapetal. Havia, também, inúmeras pequenas áreas castanho-amareladas, deprimidas e com formatos irregulares (Fig.3), alongadas ou arredondadas, próximas aos vasos do fundo, predominantes na não-tapetal. A papila e os vasos da retina estavam acentuadamente atrofiados (Fig.4).

Vinte e quatro horas após receber o fármaco, o caprino 2 apresentou diarréia líquida e diminuição do apetite. Dois dias após, o animal 
permanecia apático, com fraqueza nos membros pélvicos, e, na maior parte do tempo, com a cabeça baixa e/ou deitado. No quarto dia, apresentou ataxia e andar arrastado das pinças. As alterações oftálmicas foram similares às encontradas no caprino número 1 .

O número 3 mostrou alterações no terceiro dia após receber o fármaco, caracterizadas por leve edema da papila, com aspecto de rosado a violáceo. Os vasos maiores estavam bastante ingurgitados, tornando mais evidentes também os numerosos capilares. Essas alterações permaneceram por mais cinco a seis dias, após o que regrediram completamente. Não foram observadas alterações de comportamento que sugerissem dificuldade visual ou comprometimento nervoso.

O número 4 mostrou apenas alterações leves de postura nos primeiros três dias após a administração do fármaco. Mostrava leve incoordenação dos membros pélvicos e arrastava as pinças ao andar. No quarto dia, apresentou quadro de cegueira; andava desorientado no interior da baia, esbarrando em obstáculos. Não havia reflexo pupilar à luz, e as pupilas estavam em midríase persistente. Ao exame de fundo de olho, observaram-se papiledema, amarelamento na área tapetal nas regiões próximas à papila e congestão dos vasos da parte central do olho. No quinto dia, cessaram os sinais de incoordenação. No oitavo dia, as alterações de degeneração aguda de retina e edema de papila apenas progrediram, sendo então submetido à eutanásia.

As alterações macroscópicas restringiam-se ao bulbo ocular, exclusivamente retina e papila nos caprinos 1, 2 e 4, que apresentaram cegueira irreversível. No número 4, necropsiado na fase aguda da intoxicação, observaram-se áreas de amarelamento entremeadas por áreas esverdeadas na parte tapetal. Essas alterações foram observadas após a secção sagital de ambos os bulbos oculares. A papila e o nervo óptico estavam amolecidos, e o tom tendia para o amarelo. Nos caprinos 1 e 2, necropsiados já na fase crônica da intoxicação, observaram-se alterações semelhantes na área tapetal, além de pequenas áreas acastanhadas, levemente deprimidas, observadas também na não-tapetal. A papila estava diminuída de tamanho e esbranquiçada. Não havia evidência dos vasos. No caprino 3 e no caprino controle, a área tapetal tinha tom azul claro, e os vasos estavam bem evidentes.

Não foram observadas lesões histológicas nos cortes de encéfalo dos caprinos 1 e 2 . Na retina desses animais, as alterações foram semelhantes. Havia desaparecimento da camada nuclear interna nas regiões próximas à papila. No número 2, existiam áreas multifocais com desaparecimento das células da camada nuclear. Não foram observados neurônios na camada ganglionar e havia invasão da retina por células pigmentadas. No nervo óptico, havia astrocitose e perda da orientação das fibras nervosas e com neovascularização irregular, restos axonais, câmaras de digestão e quantidades variáveis de células Gitter. Essas alterações eram mais pronunciadas na porção intraóssea e próximas ao quiasma óptico. No caprino 3, não foram observadas alterações histológicas nos tecidos examinados.

Edema intramielínico moderado foi a principal alteração encefálica do animal 4. A vacuolização foi observada na região dos pedúnculos cerebelares, próximo aos núcleos cuneato, vago e hipoglosso, no trato óptico, nas áreas periventriculares e perimeningeais. Essas alterações ocorreram principalmente na substância branca do cerebelo e cérebro, predominantemente, perivasculares. Nessas áreas, também havia tumefação das células da glia. Em toda a extensão de nervo e quiasma ópticos ocorreu acentuado edema vacuolar. Nas alterações espongiosas, os vacúolos eram redondos ou alongados e conferiam às áreas afetadas da substância branca uma aparência rarefeita na mielina. Na retina, observaram-se tumefação e vacuolização das células nucleares, e dos neurônios da camada ganglionar (Fig.5).

Não foram observadas alterações histológicas nos nervos periféricos, na medula espinhal, no fígado e nos demais tecidos de todos os animais examinados. 


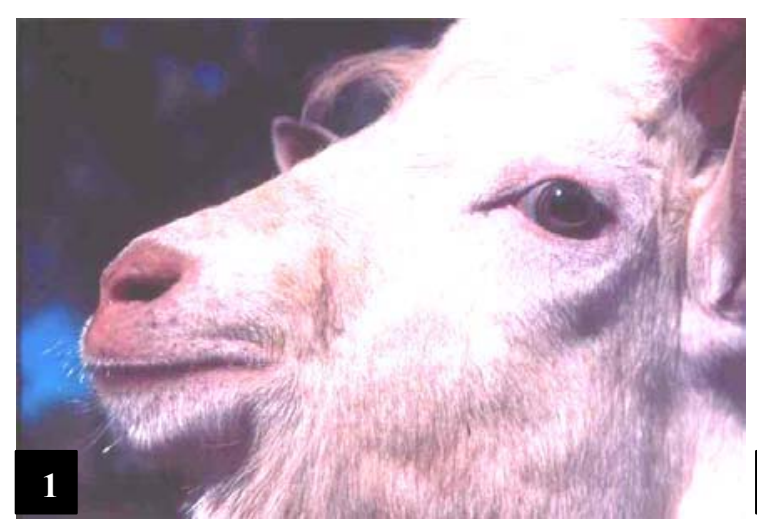

Figura 1. Caprino intoxicado por closantel. Animal exposto à luz. Observa-se midríase persistente completa.

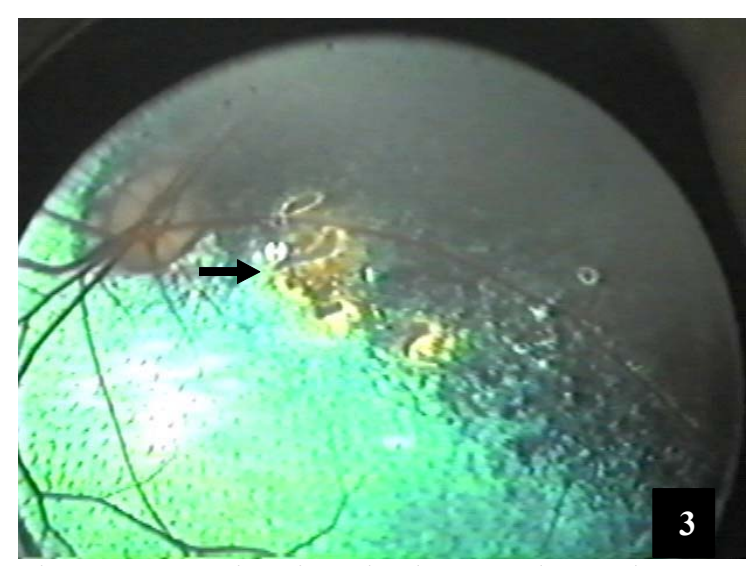

Figura 3. Caprino intoxicado por closantel. Foto obtida pela oftalmoscopia indireta 2 meses após a intoxicação. Observam-se áreas multifocais e deprimidas (seta) castanho-amareladas (necrose) na área de transição entre a área tapetal e não-tapetal.

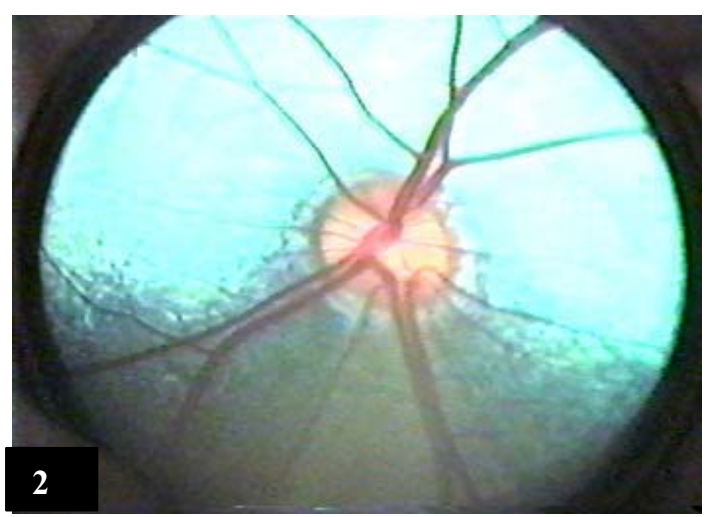

Figura 2. Caprino. Fundo de olho normal. Foto obtida pela oftalmoscopia indireta. Observa-se a área tapetal azulada, a papila e os vasos retinianos bem evidenciados.

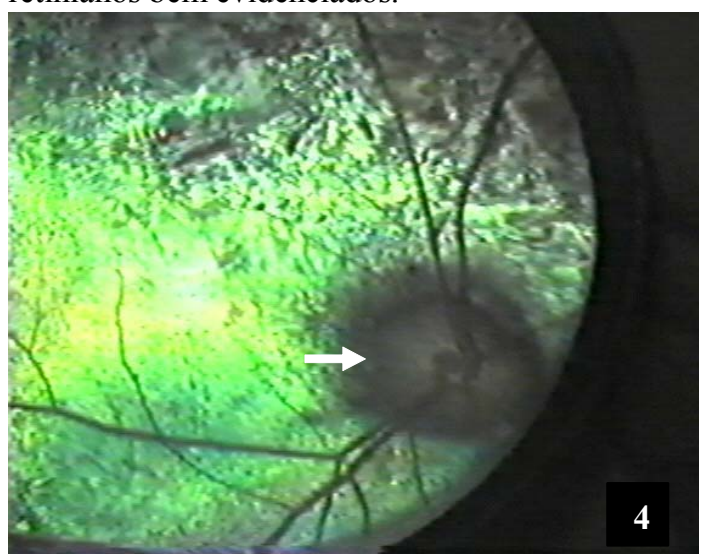

Figura 4. Caprino intoxicado por closantel. Foto obtida pela oftalmoscopia indireta 3 meses após a intoxicação. Papila óptica atrofiada e acinzentada (seta), áreas amareladas na área tapetal e atrofia vascular acentuada.

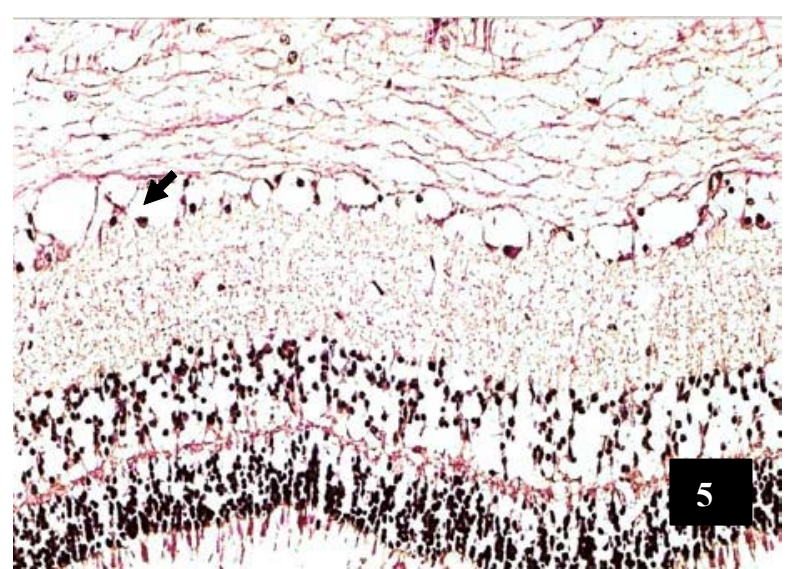

Figura 5. Fotomicrografia da retina de caprino intoxicado por closantel. Observa-se vacuolização (seta) dos neurônios da camada ganglionar e da camada nuclear da retina. Hematoxilina e eosina. 200X. 


\section{DISCUSSÃO}

A intoxicação por closantel produziu nos caprinos deste experimento alterações caracterizadas principalmente por sinais clínicos de cegueira e lesões restritas ao nervo óptico, à retina e ao encéfalo.

À oftalmoscopia, uma das primeiras alterações observadas na fase aguda foi o papiledema. A patogênese do papiledema não está bem determinada, mas algumas teorias incluem obstrução da drenagem vascular e linfática do disco, edema da substância branca cerebral, estendendo-se ao longo do nervo óptico, hipertensão intra-ocular e neoplasmias (Slatter, 1990; Miller e Gelatt, 1991). Está também incluído o efeito tóxico direto ou a hipóxia nos oligodendrócitos, originando edema intramielínico no nervo óptico. Este edema resulta em compressão do nervo no interior do canal óptico e conseqüente necrose tecidual (Jubb e Huxtable, 1993; Summers et al., 1995). O papiledema observado pela oftalmoscopia foi confirmado pela microscopia de luz, mas a patogenia não foi comprovada. $\mathrm{O}$ edema estendia-se por todo o nervo até o quiasma óptico. Possivelmente sua ocorrência deve-se a uma ação citotóxica do fármaco nos oligodendrócitos. É provável que o edema de papila apenas não seja suficiente para causar impedimento visual (Slatter, 1990). De fato, neste experimento, o caprino que recebeu $50 \mathrm{mg}$ de closantel via oral em dose única apresentou papiledema leve sem mostrar dificuldade visual aparente.

As áreas intensamente amareladas de aumento da refletividade na área tapetal foram interpretadas como um sinal oftálmico de degeneração aguda da retina. Lesão bilateral e de intensidade semelhante foi observada nos três caprinos que receberam 10 vezes a dose terapêutica quatro a cinco dias após receber o fármaco. $\mathrm{O}$ aumento da refletividade da área tapetal ocorre devido à atrofia da retina (Slatter, 1990), pois esta, quando atrofiada, aumenta a refletividade. As lesões agudas de fundo de olho também foram similares às encontradas em um cão (McEntee et al., 1995) e em ovinos (Borges et al., 1999). A atenuação dos vasos da retina também é um sinal de degeneração retiniana. Nos animais que desenvolveram cegueira, observou-se atenuação vascular na fase subaguda, e a atrofia vascular foi evidente na fase crônica do quadro de intoxicação.

A retina tem elevada atividade metabólica e suprimento sangüíneo precário, sendo particularmente suscetível a interrupções no suprimento sangüíneo. Após iniciar a hipóxia, há a morte das células da retina e a desintegração dos elementos neurais, resultando em atrofia. A retina não tem capacidade regenerativa, e as alterações nas células neurais são irreversíveis (Slatter, 1990; Brooks et al., 1999).

Alterações de postura e comportamento foram observadas apenas em dois caprinos que possuíam menor peso. $\mathrm{Na}$ intoxicação acidental (Ecco et al., 1999), na qual foi administrada a mesma dosagem do fármaco, o estado nutricional dos caprinos era de médio a regular e, conseqüentemente, maior quantidade da droga esteve disponível na corrente sangüínea. $O$ closantel se liga às proteínas plasmáticas, principalmente albumina, e a quantidade na qual a albumina é metabolizada pode influenciar a taxa de eliminação do fármaco pelo organismo (Hennessy et al., 1993). Caprinos saudáveis e bem nutridos têm nível plasmático protéico maior (Meyer e Harvey, 1998). Os animais deste experimento, embora não tenha sido feita a dosagem de proteína, poderiam ter níveis ótimos de albumina, pois se encontravam em excelente estado nutricional. Neste caso, possivelmente maiores quantidades do fármaco foram absorvidas no plasma, disponibilizando menores quantidades para os tecidos. Dessa forma, o estado nutricional pode ter retardado e/ou diminuído o efeito tóxico nos tecidos, justificando o efeito não letal, as alterações encefálicas menos intensas e a ausência de alterações hepáticas. Assim, acredita-se que, quanto mais debilitados estiverem os animais, maior o efeito da droga, e dosagens bem menores podem causar intoxicação, como já observado anteriormente (Barlow et al., 2002) em animais que receberam dosagem duas a três vezes maiores que a dosagem terapêutica.

Diarréia verde-escura, possivelmente por efeito irritativo da substância na mucosa, foi observada apenas no caprino número 1 , como relatado por Obwolo et al. (1987) e não foram vistas alterações na coloração da urina conforme descrito em um surto espontâneo da intoxicação por closantel em caprinos (Ecco et al., 1999). 
As lesões histológicas encontradas nos caprinos deste experimento foram de três tipos; degeneração espongiosa aguda do encéfalo, edema e malácia do nervo e quiasma óptico, e retinopatia degenerativa. A toxina pode chegar à retina, ao nervo óptico e ao encéfalo via vasos sangüíneos à semelhança do que aparentemente ocorre na intoxicação por $S$. imbricata (Main et al., 1981). A neuropatia óptica e a retinopatia parecem resultar de efeitos tóxicos separados. A perda de neurônios da camada ganglionar resulta de degeneração retrógrada secundária a axonopatia óptica compressiva (Gill et al., 1999). Segundo alguns autores (Main et al., 1981; Gill et al., 1999), a degeneração transináptica não ocorre, assim sendo, a lesão da retina devido à neuropatia não progride além dos neurônios ganglionares, mesmo se o nervo óptico for completamente seccionado. Nos animais deste experimento, como no surto acidental (Ecco et al., 1999), o exame histológica dos casos agudos revelou alterações primárias de edema no nervo óptico e substância branca do encéfalo. Nos casos crônicos, não foram observadas alterações no encéfalo, e as alterações no nervo óptico foram mais acentuadas na porção intraóssea.

Possivelmente, o edema intracelular e o intramielínico que se observa nos casos agudos, resultam de efeito citotóxico da droga sobre os oligodendrócitos (Van Den Bossche et al., 1979). $\mathrm{O}$ fármaco interfere com a síntese de ATP pela mitocôndria das células, propiciando o desenvolvimento de edema intracelular agudo. A perda de células ganglionares e demais elementos neurais da retina também poderiam estar relacionados com o efeito citotóxico do fármaco. Essa teoria é sustentada pelos resultados do experimento in vitro com closantel, utilizando hepatócitos de rato, cujas células tiveram depleção e paralisia de ATP mitocondrial (Bacon et al., 1998), demonstrando assim o efeito citotóxico da droga nas células somáticas.

Provavelmente as lesões crônicas observadas na camada nuclear interna da retina sejam conjuntamente decorrentes de hipóxia por compressão dos vasos devido ao edema do nervo óptico, pois nos caprinos com evolução crônica (caprinos 1 e 2) a atrofia vascular foi bastante evidente, e as lesões da retina foram progressivas. Ainda, nestes caprinos a papila estava pálida, diminuída de tamanho, com contornos irregulares e áreas negras peripapilares. De acordo com Slatter (1990), o disco óptico torna-se pálido devido à perda de capilares na sua superfície e à atrofia das fibras nervosas.

A depressão e a ataxia observadas nas intoxicações agudas pelo closantel ocorrem devido ao edema cerebral agudo e já foram observadas por outros autores (Gill et al., 1999; Ecco et al., 1999). Sinais clínicos de depressão e ataxia dos membros foram observados nos caprinos números 1 e 4 , os quais se recuperaram completamente sem apoio terapêutico. Borges et al. (1999) e McEntee et al. (1995) relataram o uso de corticóides, fluidoterapia e albumina como responsáveis pela recuperação. Possivelmente, esses sinais desaparecem quando o edema cerebral não é grave a ponto de levar à malácia e, quando esse regride, não ficam seqüelas. No caprino 2, que apresentou esses sinais, não se observou qualquer alteração histológica no encéfalo.

Segundo Summers et al. (1995), o edema intracelular afeta astrócitos e oligodendrócitos. Quando os oligodendrócitos são atingidos, a substância branca mostra uma aparência de espongiose devido ao edema intramielínico com separação da bainha de mielina na linha intraperiódica. Essa alteração foi observada no encéfalo e no nervo óptico no caprino número 4 , eutanasiado quando ainda mostrava sinais agudos da intoxicação.

No diagnóstico diferencial da intoxicação por closantel em caprinos, deve-se investigar se houve vermifugação com anti-helmínticos da família dos salicilanilídeos, ou a possível ingestão das plantas que causam alterações semelhantes.

Alterações clínicas e lesões similares têm sido descritas na sobredosagem com fármacos semelhantes em caprinos e ovinos; a rafoxanida (salicilanilídea) em ovinos (Prozesky e Pienaar, 1977) e a associação de closantel + albendazole em ovinos e caprinos (Obwolo et al., 1989).

As intoxicações de plantas tóxicas como Helichrysum argyrosphaerum (Basson et al., 1975; Van der Lugt et al., 1996), Stypandra imbricata (Main et al., 1981) e Stypandra glauca 
(Whittington et al., 1988) causam midríase bilateral persistente e lesões de espongiose no cérebro e nervo óptico. As lesões de retina são de atrofia, porém pode haver, também, hipertrofia das células do epitélio pigmentar (Main et al., 1981).

Em casos de intoxicação pela samambaia (Pteridium aquilinum), as alterações são basicamente de degeneração progressiva da retina seguida de atrofia. Não são descritas alterações no nervo óptico e cérebro (Hirono et al., 1993). No Brasil, não há relatos relacionados à cegueira causada pela ingestão de samambaia em animais, e as demais plantas relacionadas não são encontradas no território nacional.

A superdosagem por closantel causa danos irreversíveis nos sistema ocular e neural como pode ser observado pela oftalmoscopia e confirmado pela histopatologia. Acredita-se que, para a prevenção desses problemas, cuidados maiores com relação à dosagem e peso devem ser tomados principalmente em animais com menor peso ou mal nutridos. Outrossim, que se dê preferência a formulações com concentrações menores ou associações.

\section{AGRADECIMENTOS}

Aos doutores Álvaro Rossi e Gentil F. Gonçalves pelo apoio na avaliação oftalmoscópica.

\section{REFERÊNCIAS BIBLIOGRÁFICAS}

BACON, J.A.; ULRICH, R.G.; DAVIS, J.P. et al. Comparative in vitro effects of closantel and selected B - ketoamide anthelmintics on a gastrointestinal nematode and vertebrate liver cells. J. Vet. Pharmacol. Ther., v.21, p.190-198, 1998.

BARLOW, A.M.; SHARPE, J.A.E.; KINCAID, E.A. Blindness in lambs due to inadvertent closantel overdose. Vet. Rec., v.151, p.25-26, 2002.

BASSON, P.A.; KELLERMAN, T.S.; ALBL, P. et al. Blindness and encefalopathy caused by Helichrysum argyrosphaerum (Compositae) in sheep and cattle. Onderstepoort J. Vet. Res., v.42, p.135-148, 1975.

BORGES, A.S.; MENDES, L.C.N.; ANDRADE, A.L. et al. Optic neuropathy in sheep associated with overdosage of closantel. Vet. Human Toxicol., v.41, p.378-380, 1999.

BROOKS, D.E.; KOMÀROMY, A.M.; KÄLLBERG, M.A. Comparative retinal ganglion cell and optic nerve morphology. Vet. Ophthalmol., v.2, p.3-11, 1999.

BUTTON, C.; JERRETT, I.; ALEXANDER, P. et al. Blindness in kids associated with overdosage of closantel. Aust. Vet. J., v.64, p.226, 1987.

CANAVESSI, A.M.O.; SARTOR, I.F.; ALMEIDA, C.T. Intoxicação em ovinos pelo closantel. Vet. Not., v.4, p.121-123, 1998.

ECCO, R.; GAVA, A.; GRAÇA, D.L. et al. Intoxicação por closantel em caprinos - Relato de caso. In: ENCONTRO NACIONALDE PATOLOGIA VETERINÁRIA, 9., 1999, Belo Horizonte. Anais... Belo Horizonte. p.91. (Resumo).

GILL, P.A.; COOK, R.W.; BOULTON, J. G. et al. Optic neuropathy in closantel toxicosis of sheep and goats. Aust. Vet. J., v.77, p.259-261, 1999.

GUERRERO, J. Closantel: a review of its antiparasitic activity. Prev. Vet. Med., v.2, p.317$327,1984$.

HENESSY, D.R.; SANGSTER, N.C.; STEEL J.W. et al. Comparative pharmacokinetic disposition of closantel in sheep and goats. $J$. Vet. Pharmacol. Therap., v.16, p. 254-260, 1993.

HIRONO, I.; ITO, M.; YAGYU, S. et al. Reproduction of progressive retinal degeneration (bright blindness) in sheep by administration of Ptaquiloside contained in bracken. J. Vet. Med. Sci., v.55, p.973-983, 1993.

JUBB, K.V.J.; HUXTABLE, C.R. The nervous system. In: JUBB, K.V.J.; KENNEDY, P.C.; PALMER, N. (Eds.). Pathology of domestic animals. San Diego: Academic, 1993. v.1, p.267530.

MAIN, D.C.; SLATTER, D.H.; HUXTABLE, C.R. et al. Stypranda imbricata ("blindgrass") toxicosis in goats and sheep - clinical and pathologic findings in 4 fields cases. Aust. Vet. J., v.57, p.132-135, 1981.

Mc ENTTEE, K.M.; GRAUWELS, M.; CLERCX, C. Closantel Intoxication in a dog. Vet. Human Toxicol., v.37, p.234-236, 1995. 
MEEUS, P.F.M. Treatment of bovine demodecosis with closantel. Vet. Rec., v.143, p.451-452, 1998 .

MEYER, D.J.; HARVEY, J.W. (Eds). Veterinary laboratory medicine. Interpretation \& diagnosis. 2.ed. Philadelphia: Saunders company. 1998. $373 p$.

MICHIELS, M.; MEULDERMANS, W.; HEYKANT, S. The metabolism and fate of closantel (Flukiver) in sheep and cattle. Drug Metab. Rev., v.18, p.235-251, 1987.

MILLER, T.R.; GELLAT, K.N. Food animal ophthalmology. In: GELLAT, K.N. (Ed). Veterinary ophthalmology. 2.ed. Philadelphia: Lea \& Febiger, 1991. p.611-665.

OBWOLO, M.J.; ODIAWO, G.O.; OGAA, J.S. Toxicity of a closantel-albendazole mixture in a flock of sheep and goats. Aust. Vet. J., v.66, p.229, 1989.

PÉREZ, O.A.; NEGRETTE, S.M.; COPPO, J.A. Evaluacion del efecto provocado por Closantel en distintas dosificaciones sobre el aparato ocular del bovino. Vet. Arg., v.5, p.700-706, 1988.
PROZESKY, L.; PIENAAR, J.G. Amaurosis in sheep resulting from treatment with rafoxanide. Onderstepoort J. Vet. Res., v.44, p.257-260, 1977.

SLATTER, D. H. (Ed). Fundamentals of veterinary ophthalmology. 2 ed. Philadelphia: W.B. Sauders, 1990. 630p.

SUMMERS, A B.; CUMMINGS, J.F.; De LAHUNTA A. (Eds). Veterinary neuropathology. St. Louis: Mosby, 1995.

VAN DEN BOSSCHE, H.; VERHOEVEN, H.; VANPARUS, $O$. et al. Closantel, a new antiparasitic hydrogen ionophore. Arch. Int. Physiol. Biochim., v.87, p.851-853, 1979.

VAN DER LUGT, J.J.; OLIVIER, J.P. Status spongiosis, optic neurophaty, and retinal degeneration in Helichrysum argyosphaerum poisoning in sheep and goat. Vet. Pathol., v.33, p.495-502, 1996.

WHITTINGTON, R.J.; SEARSON, J.E.; WHITTAKER, S.J. et al. Blindness in goats following ingestion of Stypandra glauca. Aust.Vet. J., v.65, p. 176-181, 1988. 